İlköğretim Çocuklarında Uyku Bozukluğu Sıklığı ve Obezite ile Îlişkisi

\title{
Prevalence of Sleep Disorders in Primary School Children and its Relationship with Obesity
}

\author{
Hasan Durmuş* (0000-0001-5719-1475), Yavuzalp Solak** (0000-0001-5274-7606), Erhan Kaya ${ }^{\star \star \star ~}(0000-0001-7458-$ \\ 3024), Halil Canbolat** (0000-0001-5669-0651) \\ ^Erciyes Üniversitesi Tıp Fakültesi, Halk Sağlığı Anabilim Dall, Kayseri, Türkiye \\ *^Dörtyol İlçe Sağlık Müdürlüğü, Hatay, Türkiye \\ ***Kadirli İlçe Sağlık Müdürlüğü, Osmaniye, Türkiye
}

\begin{abstract}
Anahtar kelimeler
Uyku bozukluğu, obezite, adölesan, uyku
\end{abstract}

Keywords

Sleep disorder, obesity, adolescent, sleep

Geliş Tarihi/Received : 28.05.2021

Kabul Tarihi/Accepted : 08.09.2021

DOI: $10.4274 /$ jcp.2021.38980

Yazışma Adresi/Address for Correspondence: Dr. Yavuzalp Solak , Dörtyol İlçe Sağlık Müdürlüğü, Hatay, Türkiye

E-posta: yavuzalp80@gmail.com

\section{$\ddot{O} z$}

Giriş: Obezite sadece erişkinlerde değil çocuklarda da tüm dünyada giderek yaygınlaşan bir sağlık sorunudur. Türkiye'de obezite oranları bölgelere göre $\% 4,5$ ile \% 15,9 arasında değişmektedir. Düzenli ve yeterli uyku, sağlıklı yaşamın devam ettirilmesinin yanı sıra fiziksel, bilişsel ve duygusal gelişim için de önemlidir. Çalışmanın amacı ilköğretim çağındaki çocuklarda uyku sorunları düzeyinin, nedenlerinin ve obezite ile ilişkisinin belirlenmesidir.

Gereç ve Yöntem: Çalışma tanımlayıcı niteliktedir. Katılımcıların sosyodemografik bilgilerini içeren sorular ile çocukların uyku bozukluğunu değerlendirmek için Bruni tarafından geliştirilen ve Akçay tarafından Türkçe geçerlilik güvenilirliği yapılan çocuklarda uyku bozukluğu ölçeği ilköğretim çağındaki çocukların ebeveynleri tarafından cevaplanmıştır. Veriler SPSS programında değerlendirilmiş, $\mathrm{p}<0.05$ anlamlı kabul edilmiştir.

Bulgular: Çalışmaya 6 ile 14 yaş arasındaki 519 öğrenci katılmıştır. Öğrencilerin $\% 12,5$ 'i (65 kişi) ise obez olarak tespit edilmiştir. Uyku bozukluğu olan öğrenci oranı \%59,0 (306 kişi) olarak bulunmuştur. Ekonomik durumu kötü olan, anne babasıyla aynı yatağı paylaşan, kronik bir rahatsızlığı bulunan, cep telefonu olan ve babasının eğitim düzeyi düşük olan çocuklarda uyku bozukluğu oranı daha yüksek görülürken obezite durumu ile uyku bozukluğu arasında anlamlı bir ilişki tespit edilememiştir.

Sonuç: Uyku bozukluğu olan çocuk oranı bir hayli yüksektir. Çocuk gelişimi ve çocuğun kognitif fonksiyonları göz önüne alındığından uyku bozukluğunun ve yol açan faktörlerin giderilmesi önem arz etmektedir. Çalışmamızda uyku bozukluğu ile obezite arasında ilişki gösterilemese de, ulusal düzeyde yapılacak daha büyük ölçekli çalışmalarla obezite ve uyku bozukluğu arasındaki ilişki daha net bir şekilde ortaya konularak konuya politika yapıcıların dikkati çekilmelidir.

\begin{abstract}
Introduction: Obesity is an increasingly common health problem not only in adults but also in children all over the world. Obesity rates in Turkey vary between $4.5 \%$ and $15.9 \%$ according to regions. Regular and adequate sleep is important for maintaining a healthy life as well as for physical, cognitive and emotional development. The aim of the study is to determine the level of sleep problems in primary school children, their causes and their relationship with obesity.

Materials and Methods: The study is descriptive. The sleep disorder scale in children, which was developed by Bruni to evaluate the sleep disorder of the children and whose Turkish validity was verified by Akçay, was answered by the parents of children of primary school age with questions containing the socio-
\end{abstract}


demographic information of the participants. The data were evaluated in the SPSS program, $\mathrm{p}<0.05$ was considered significant.

Results: 519 students between the ages of 6 and 14 participated in the study. $12.5 \%$ of the students (65 people) were found to be obese. The rate of students with sleep disorders was found to be $59.0 \%$ (306 people). While the rate of sleep disorders was higher in children with poor economic status, sharing the same bed with their parents, having chronic illness, having mobile phone, and low education level of their father, no significant relationship was found between obesity and sleep disorders.

Conclusion: The rate of children with sleep disorders is quite high. Since child development and cognitive functions of the child are taken into consideration, it is important to eliminate sleep disorder and the factors that cause it. Although our study could not show a relationship between sleep disorder and obesity, policy makers' attention should be drawn to the issue by revealing the relationship between obesity and sleep disorder more clearly with larger-scale studies to be conducted at the national level.

\section{Giriş}

Erişkinlerde olduğu gibi çocukluk çağında da obezite tüm dünyada giderek artarak önemli bir sağlık riski halini almıştır. Çocukluk çağında (5-19 yaş) 1975 yılında \%4 olan fazla kilolu ve obez oranı 2016 yılında $\% 18$ 'e yükselmiş olup dünyada 340 milyon obez çocuk bulunmaktadır (1-3). Türkiye' de yapılan araştırmalarda çocukluk çağı obezite sıklığ $1 \% 8,2$ ile \%9,9 arasında değişmektedir (4). Avrupa bölgesi çocukluk çağ1 obezitesinin izlendiği (COSI çalışması) araştırmada Avrupa'da en yüksek obezite oranı İspanya $(\% 17,7)$, Malta $(\% 17,2)$ ve İtalya'da $(\% 16,8)$ izlenmiş ve anne sütünün obeziteyle olan ilişkisi;anne sütü alma süresi arttıkça, obezite oranının azaldı ğı gösterilmiştir (5). COSI Türkiye çalışmasının sonuçlarına göre Türkiye genelinde obezite oranı \%9,9, Akdeniz Bölgesinde obezite oranı \%9,2 iken \%15,9 ile en yüksek obezite oranı Ege Bölgesindedir. Obezite oranın en düşük olduğu bölgeler Güneydoğu, Kuzeydoğu ve Ortadoğu Anadolu Bölgeleri olup oranları sirasiyla \% 4,5, \%5,4 ve $\% 5,5$ 'tir (6). Obezite gelişimi endojen nedenler olarak kabul edilen;genetik nedenler, sendromik hastalıklar ve endokrin nedenlerden kaynaklanabildiği gibi, aşırı gıda alımı, sedanter yaşam, dengesiz beslenme gibi eksojen nedenler olarak kabul edilen nedenlere de bağlı olabilir $(7,8)$.

Uyku, çocukluk çağında sadece normal fiziksel gelişim için değil normal duygusal gelişim, dikkat ve kognitif fonksiyonlar için de gerekli görülmektedir (9). Sağlıklı bir yaşamın devam ettirilebilmesi için düzenli ve yeterli uyku gerekliliği bilinmekle birlikte uyku sorunlarının obezite ile ilişkisini gösteren çalışmalar giderek artmaktadır $(10,11)$. Çocuklarda uyku bozukluğu \%25-\%50 arasında değişmektedir (12). Uyku sorunları, yeme alışkanlığında değişiklikler, gün içinde uyku hali ve hormonal değişimler meydana getirebilmekte, vücut metabolizmasını olumsuz yönde etkileyerek obeziteye neden olabilmektedir $(10,13)$. Uyku bozuklukları içerisinde; uykusuzluk bozukluğu, aşırı uyuma, narkolepsi, solunum ile ilgili problemler, sirkadiyen ritimle ilgili problemler, parasomniler ve diğer türler bulunmaktadır (14). Bu kapsamda çeşitlilik gösteren uyku bozukluğunun belirlenmesinde basit yöntemler ile aile gözlemi, bazen çocuğunun kendi gözlemi önem arz etmektedir (15). Daha sonra bu uyku bozukluğunun belirlenmesi için klinik değerlendirme ve nedene yönelik tedavi süreci yürütülmesi gerekmektedir (16). Tarama niteliğinde olan ölçekler kullanılarak çocuklarda uyku problemlerinin belirlenmesi genel olarak kabul görmüş ve yaygın olarak kullanılmaktadır (17).

Bu çalışmada amaç ilköğretim döneminde bulunan çocuklarda uyku sorunları düzeyinin belirlenmesi, nedenleri ve obezite ile ilişkisinin belirlenmesidir.

\section{Gereç ve Yöntem}

Tanımlayıcı nitelikteki bu çalışma 2021 yılı Şubat-Mart aylarında Hatay Dörtyol Milli Eğitim Müdürlügü̈'ne bağlı okullarda velilerle yüz yüze görüşerek yapılmıştır. Örneklem büyüklüğüu G power programı ile, düşük etki büyüklüğü alınarak $\alpha: 0.05$, güç \%99 ve toplumda uyku bozukluğunun $\% 50$ olduğu varsayılarak 455 olarak hesaplanmıştır. Örneklem büyüklüğüne ulaşmak için 550 çocuğa ulaşılmış olup, 17 çocuğun velisine ulaşılamamış, 14 veli çalışmaya katılmayı kabul etmemiş ve nihayet çalışma 519 kişi ile tamamlanmıştır. Çalışmaya katılan çocukların ailelerinden yazılı aydınlatılmış onam formu alınmıştır. Araştırma öncesi Hatay Dörtyol İlçe Milli Eğitim Müdürlügüu'nden gerekli izinler ve Hatay Mustafa Kemal Üniversitesi Girişimsel Olmayan Klinik Araştırmalar Etik Kurulu'ndan 14.01.2021 tarih ve 17 numaralı karar ile etik onay alınmıştır.

Çalışmada literatür taranarak hazırlanan anket formu kullanılmış olup birinci bölümde sosyodemografik bilgiler ile çocuğun sağlık durumu ve ailenin eğitim durumu ile ilgili sorular ayrıca çocuğun 
boy-kilo ölçümleri bulunmaktadır. Çocukların boy ve kilo değerleri araştırmacı tarafından ölçülerek kayıt altına alınmıştır. İkinci bölümde ise ilk olarak Bruni tarafından uygulanan Çocuklarda Uyku Bozukluk Ölçeğinin (ÇUBÖ) Akçay tarafından 2020'de geçerlilik güvenilirliği yapılan ve Türkçe'ye uyarlanan anket uygulanmıştır (17). Beşli Likert tipi ölçekte 1 'hiçbir zaman', 5 ise 'her zaman' ile anlamina gelmekte olup "Uykuya dalma ve uykuyu devam ettirme problemleri (UDUDEP) (7 Soru), Uykuda solunum bozuklukları (USB) (3 Soru), Uyanma bozuklukları (UB) (3 Soru), Uyku-uyanma geçiş bozuklukları (UUGB) (4 Soru), Aşırı uyku eğilimi bozuklukları (AUEB) (5 Soru), Uykuda aşırı terleme (UAT) (2 Soru)" olmak üzere 6 alt ölçekten oluşmaktadır. Alt ölçeklerden alınan puanların toplamı ÇUBÖ puanını vermektedir. Yüksek puanlar uyku bozukluğunun daha fazla olduğunu göstermektedir. Kesme değeri olarak 34 puan kabul edilmiş olup 34 ve üzeri puanlar uyku bozukluğu olan çocukları göstermektedir.

İstatistiksel değerlendirmeler için SPSS 19 for Windows paket programı kullanılarak istatistiksel analiz olarak frekans tabloları, ÇUBÖ ölçeğinden alınan puan ortalamaları, ki-kare testi, t-testi, normal dağılıma uygunluk testleri, anova, Post-hoc analizler, Mann-Whitney $U$ testi yapılmıştır. $p<0,05$ anlamlı olarak kabul edilmiştir. Araştırmanın bağımsız değişkenleri;Demografik bilgiler, boy- kilo değerleri ve kronik hastalığa sahip olma ve ameliyat olma durumu, bağımlı değişkeni ise, ÇUBÖ ölçeğinden alınacak puanlardır.

Çocukların persentil değerleri hesaplanırken Neyzi O ve ark. (18) yapmış olduğu Türk çocukları için belirlenen değerler kullanılmış olup çocukların cinsiyetlerine ve yaşlarına göre 5 percentil değeri altı zayıf, 5-85 percentil değerleri arası normal, 8595 percentil değerleri arası fazla kilolu, 95 percentil değeri üzeri ise obez olarak sınıflandırılmıştır.

\section{Bulgular}

Çalışmaya yaşları 6 ile 14 arasında değişmekte olan 519 öğrenci katılmış olup yaş ortalamaları 9,68 $\pm 2,11$ 'dir. Öğrencilerin \%53,6's1 (278 kişi) kızdır. Öğrencilerin \%74,0'ının (384 kişi) anketini annesi, $\% 23,7$ 'sinin anketini (123 kişi) babası doldurmuştur. Katılımc1lara ait genel özellikleri Tablo 1'de gösterilmiştir.

\begin{tabular}{|c|c|c|}
\hline & $\mathrm{n}$ & $\%$ \\
\hline $\begin{array}{l}\text { Cinsiyet } \\
\mathrm{K}_{1 \mathrm{z}} \\
\text { Erkek }\end{array}$ & $\begin{array}{l}278 \\
241\end{array}$ & $\begin{array}{l}53,6 \\
46,4\end{array}$ \\
\hline $\begin{array}{l}\text { Anketi dolduran } \\
\text { Annesi } \\
\text { Babası } \\
\text { Diğer }\end{array}$ & $\begin{array}{l}384 \\
123 \\
12\end{array}$ & $\begin{array}{l}74,0 \\
23,7 \\
2,3\end{array}$ \\
\hline $\begin{array}{l}\text { Kendisine ait oda } \\
\text { Var } \\
\text { Yok }\end{array}$ & $\begin{array}{l}382 \\
137\end{array}$ & $\begin{array}{l}73,6 \\
26,4\end{array}$ \\
\hline $\begin{array}{l}\text { Kardeşi var mı? } \\
\text { Kardeşi yok } \\
\text { Kendinden büyük kardeşi var } \\
\text { Kendinden küçük kardeşi var } \\
\text { Hem büyük hem küçük kardeşi var }\end{array}$ & $\begin{array}{l}25 \\
178 \\
183 \\
133\end{array}$ & $\begin{array}{l}4,8 \\
34,3 \\
35,3 \\
25,6\end{array}$ \\
\hline $\begin{array}{l}\text { Uyuduğu yer } \\
\text { Odada tek başına } \\
\text { Kardeşi ile aynı odada farklı yatakta } \\
\text { Anne babasıyla aynı odada farklı } \\
\text { yatakta } \\
\text { Anne babasıyla aynı yatakta }\end{array}$ & $\begin{array}{l}144 \\
336 \\
23 \\
16\end{array}$ & $\begin{array}{l}27,7 \\
64,7 \\
4,4 \\
3,1\end{array}$ \\
\hline $\begin{array}{l}\text { Cep telefonu var mi? } \\
\text { Evet } \\
\text { Hayır }\end{array}$ & $\begin{array}{l}38 \\
481\end{array}$ & $\begin{array}{l}7,3 \\
92,7\end{array}$ \\
\hline $\begin{array}{l}\text { Kablosuz internet var mı? } \\
\text { Evet } \\
\text { Hayır }\end{array}$ & $\begin{array}{l}306 \\
213\end{array}$ & $\begin{array}{l}59,0 \\
41,0\end{array}$ \\
\hline $\begin{array}{l}\text { Cerrahi bir operasyon geçirdi mi? } \\
\text { Evet } \\
\text { Hayır }\end{array}$ & $\begin{array}{l}84 \\
435\end{array}$ & $\begin{array}{l}16,2 \\
83,8\end{array}$ \\
\hline $\begin{array}{l}\text { Kronik bir rahatsızlığı var mı? } \\
\text { Evet } \\
\text { Hayır }\end{array}$ & $\begin{array}{l}53 \\
466\end{array}$ & $\begin{array}{l}10,2 \\
89,8\end{array}$ \\
\hline $\begin{array}{l}\text { Percentil değeri } \\
\text { Zayıf } \\
\text { Normal } \\
\text { Fazla kilolu } \\
\text { Obez }\end{array}$ & $\begin{array}{l}31 \\
353 \\
70 \\
65\end{array}$ & $\begin{array}{l}6,0 \\
68,0 \\
13,5 \\
12,5\end{array}$ \\
\hline $\begin{array}{l}\text { Uyku bozukluğu } \\
\text { Var } \\
\text { Yok }\end{array}$ & $\begin{array}{l}306 \\
213\end{array}$ & $\begin{array}{l}59,0 \\
41,0\end{array}$ \\
\hline Toplam & 519 & 100 \\
\hline
\end{tabular}

Öğrenciler uyumadan ortalama $2,05 \pm 1,10$ saat önce bir şeyler yiyip içmektedirler. Gün içerisinde hiç çay tüketmeyen çocuk oranı \%26,8 (139 kişi), 1 bardak çay tüketen öğrenci oranı \%48,0 (249 kişi), 2 bardak çay tüketen öğrenci oranı \%17,3 (90 kişi), 3 ve daha fazla bardak çay tüketen çocuk oranı ise \%7,9'dur (41 kişi). Çocukların \%91,7'si (476 kişi) hiç kahve 
tüketmemektedir. 1 bardak tüketenlerin oranı $\% 7,7$ (40 kişi), 2 bardak tüketenlerin oran 1 ise \%0,6 (3 kişi) olarak bulunmuştur. Hiç kola tüketmeyen çocuk oranı \%76,3 (396 kişi) günde 1 bardak tüketenlerin oran1 $\% 14,1$ (73 kişi), 2 ve daha fazla tüketenlerin oranı ise $\% 9,6$ 'dır (50 kişi).

Çalışmaya dahil edilen çocukların en sık geçirdiği cerrahi operasyon \%25,0 (21 kişi) ile geniz eti operasyonu olurken bunu \%22,6 (19 kişi) ile bademcik operasyonu, \%14,3 (12 kişi) ile fitık operasyonu, $\% 10,7$ (9 kişi) ile kemik kırıkları takip etmektedir. Çocuklarda en sık görülen kronik hastalık \%24,5 (13 kişi) ile alerji olurken bunu \%22,6 (12 kişi) ile astım ve \%9,4 (5 kişi) ile bronşit takip etmektedir.

Öğrencilerin \%13,5'si (70 kişi) fazla kilolu, $\% 12,5$ 'si (65 kişi) ise obez olarak tespit edilmiştir. Öğrencilerin \%59,0’1 (306 kişi) uyku bozukluğuna sahip olarak tespit edilmiştir.

Kız öğrencilerde uyku bozukluğu oranı \%56,8 (158 kişi) erkek öğrencilerde ise \%61,4 (148 kişi) olarak bulunmuştur. ÇÜBO alt gruplarına ait dağılım Tablo 2'de gösterilmiştir.

Baba eğitim düzeyi ilköğretim, ekonomik durumu kötü, anne-babasıyla beraber yatan, cep telefonu ve kronik hastalığı olanlarda ÇÜBO puan1

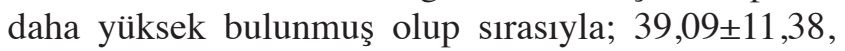
$44,78 \pm 15,47,45,13 \pm 12,29,41,55 \pm 12,50,42,58 \pm 13,63$ olarak bulunmuştur. ÇÜBO puanı ile değişkenlerin karşılaştırması Tablo 3'de sunulmuştur.

Uyku bozukluğu ile obezite durumu karşılaştırıldığında aralarında anlamlı bir fark bulunmamış olmakla birlikte zayıf ve normalin üstünde olan çocuklarda daha yüksek oranda uyku bozukluğu görülmüştür.

\section{Tartışma}

Çalışmamızda 6 ile 14 yaşları arasında öğrenciler

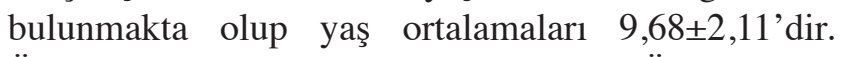
Öğrencilerin \%53,6's1 kızdır. Öğrencilerin sosyodemografik bilgileri, antropometrik ölçümleri ve uyku bozukluğu için ÇUBÖ skoru bilgileri ile veriler değerlendirilmiştir. Çalışmamızda obezite prevalansı $\% 12,5$ olarak tespit edilmiştir (Tablo 1). Ayrıca öğrencilerin \%13,5'i fazla kiloludur. Türkiye Sağlık Bakanlığı Çocukluk Çağı Şişmanlık Araştırmasında tüm bölgelerde ilkokul ikinci sınıf öğrencilerinde obez ve fazla kilolu öğrenci oranları sırayla 9,9 ve 14,6 iken, 11-14 yaş arasında Türkiye'de yapılan başka

\begin{tabular}{lllll}
\hline \multicolumn{5}{c}{ Tablo 2. ÇUBÖ ve alt ölçekleri puan dağılımı } \\
\hline Ölçek & $\begin{array}{l}\text { Soru } \\
\text { sayısı }\end{array}$ & $\begin{array}{l}\text { Alınan } \\
\text { en } \\
\text { düşüik } \\
\text { puan }\end{array}$ & $\begin{array}{l}\text { Alınan } \\
\text { en } \\
\text { yüksek } \\
\text { puan }\end{array}$ & $\begin{array}{l}\text { Alınan ortalama } \\
\text { Toplam puan } \pm \text { SS }\end{array}$ \\
\hline ÇUBÖ & 24 & 24 & 83 & $36,99 \pm 9,13$ \\
UDUDEP & 7 & 7 & 27 & $12,29 \pm 3,49$ \\
USB & 3 & 3 & 15 & $3,89 \pm 1,54$ \\
UB & 3 & 3 & 13 & $4,13 \pm 1,60$ \\
UUGB & 4 & 4 & 18 & $5,84 \pm 2,28$ \\
AUEB & 5 & 5 & 23 & $7,93 \pm 3,07$ \\
UAT & 2 & 2 & 10 & $2,92 \pm 1,64$
\end{tabular}

ÇUBÖ: Çocuklarda Uyku Bozukluğu Ölçeği, UDUDEP: Uykuya dalma ve Uykuya devam etme problemleri, USB: Uyku Solunum Bozuklukları, UB: Uyanma Bozuklukları, AUEB: Aşırı Uyku Eğilimi Bozuklukları, UAT: Uykuda Aşırı Terleme, SS:Standart sapma

bir çalışmada obezite prevalansı \%10,3'tür. $(6,19)$ Avrupa ülkelerinde $\% 17,7$ ye ulaşan çocukluk çağ 1 obezite oranları rapor edilmiştir (5). Obezite prevalansı çalışmamızda yüksektir. Çocuk ve ergenlerde obezite hem Türkiye'de hem de dünyada son y1llarda önemli ölçülerde artış göstermiş, içinde bulunduğumuz yüzyıl içerisinde en ciddi küresel sağlık sorunlarından biri olmuştur $(20,21)$. Çocukluk çağında artan obezite yükü ile komorbid durumlar daha yaygin hale gelmektedir (22). Obezite, kardiyovasküler hastalıklar, solunum yolu hastalıkları, kanserler, diyabet ve osteoartrit gibi birçok hastalık ve erken ölüm için önemli bir risk faktörüdür $(21,23)$.

Çalışmamızda öğrencilerde uyku bozukluğu prevalans1 ise \%59,0 bulundu (Tablo 1). Uyku bozukluğu erkeklerde $(\% 61,4)$ kızlara $(\% 56,8)$ göre biraz daha yüksekti. Erkeklerin ÇUBÖ puan ortalamaları da anlamlı olmamakla beraber kızlardan biraz daha yüksek olarak bulunmuştur (Tablo 3). Literatürde çocuklarda uyku bozukluğu oranının \%2232 arasında olduğu çalışmalar izlenmiştir. Kabel ve ark. (24) çalışmasında uyku bozukluğu genel olarak kızlarda yüksek, Lewien ve ark. çalışmasında ise çocukluk döneminde uyku bozukluğu erkeklerde, ergen dönemde ise k1zlarda daha yüksektir (24-26). Cinsiyete göre uyku süre ve düzenindeki farklılıklar cinsiyet hormonları ile ilişkilendirilmiştir (27). Uyku bozukluğunun kız ve erkeklerde farklı oranlarda görülmesinin sebebi biyolojik nedenler ile olabildiği gibi kültürel farklılıklardan da kaynaklanabilir (28). Çalışmamızda uyku üzerinde etki gösteren bu çevresel ve genetik faktörler, bu farklılığı açıklayabilir. Sağlıklı 


\begin{tabular}{|c|c|c|c|}
\hline \multirow{2}{*}{ Özellikler } & \multicolumn{2}{|r|}{ ÇÜBO } & \multirow[b]{2}{*}{$\mathrm{p}^{*}$} \\
\hline & $\mathrm{n}$ & Mean \pm SD & \\
\hline $\begin{array}{l}\text { Cinsiyet } \\
\mathrm{K}_{1 \mathrm{z}} \\
\text { Erkek }\end{array}$ & $\begin{array}{l}278 \\
241\end{array}$ & $\begin{array}{l}36,55 \pm 8,87 \\
37,50 \pm 9,41\end{array}$ & 0,241 \\
\hline $\begin{array}{l}\text { Anne Eğitimi? } \\
\text { İlköğretim } \\
\text { Lise } \\
\text { Üniversite ve üzeri }\end{array}$ & $\begin{array}{l}213 \\
136 \\
170\end{array}$ & $\begin{array}{l}37,71 \pm 10,2 \\
36,08 \pm 8,76 \\
36,82 \pm 7,91\end{array}$ & 0,255 \\
\hline $\begin{array}{l}\text { Baba Ĕ̆itim } \\
\text { İlköğretim } \\
\text { Lise } \\
\text { Üniversite ve üzeri }\end{array}$ & $\begin{array}{l}161 \\
140 \\
218\end{array}$ & 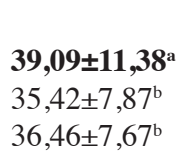 & 0,001 \\
\hline $\begin{array}{l}\text { Ekonomik Durum } \\
\text { Kötü } \\
\text { Orta } \\
\text { İyi }\end{array}$ & $\begin{array}{l}27 \\
279 \\
213\end{array}$ & $\begin{array}{l}\mathbf{4 4 , 7 8} \pm \mathbf{1 5}, \mathbf{4 7}^{\mathrm{a}} \\
37,08 \pm 8,78^{\mathrm{b}} \\
35,90 \pm 8,03^{\mathrm{b}}\end{array}$ & 0,000 \\
\hline $\begin{array}{l}\text { Kendisine ait oda olma } \\
\text { durumu? } \\
\text { Var } \\
\text { Yok }\end{array}$ & $\begin{array}{l}382 \\
137\end{array}$ & $\begin{array}{l}37,04 \pm 9,03 \\
36,88 \pm 9,43\end{array}$ & 0,863 \\
\hline $\begin{array}{l}\text { Uyumudan önce } 2 \text { saat } \\
\text { içinde yeme-içme? } \\
\text { Var } \\
\text { Yok }\end{array}$ & $\begin{array}{l}373 \\
146\end{array}$ & $\begin{array}{l}37,05 \pm 8,75 \\
36,85 \pm 10,065\end{array}$ & 0,840 \\
\hline $\begin{array}{l}\text { Uyuduğu Yer } \\
\text { Odada tek başına } \\
\text { Kardeşi ile aynı odada farklı } \\
\text { yatakta } \\
\text { Anne babasıyla aynı odada } \\
\text { farklı yatakta } \\
\text { Anne babasıyla beraber }\end{array}$ & $\begin{array}{l}144 \\
336 \\
23 \\
16\end{array}$ & $\begin{array}{l}37,65 \pm 9,16^{\mathrm{b}} \\
36,37 \pm 8,83^{\mathrm{b}} \\
36,39 \pm 8,32^{\mathrm{b}} \\
\mathbf{4 5 , 1 3} \pm \mathbf{1 2 , 2 9 ^ { \mathrm { a } }}\end{array}$ & 0,007 \\
\hline $\begin{array}{l}\text { Kablosuz Internet } \\
\text { Var } \\
\text { Yok }\end{array}$ & $\begin{array}{l}306 \\
213\end{array}$ & $\begin{array}{l}37,01 \pm 8,72 \\
36,97 \pm 9,71\end{array}$ & 0,956 \\
\hline $\begin{array}{l}\text { Cep Telefonu } \\
\text { Var } \\
\text { Yok }\end{array}$ & $\begin{array}{l}38 \\
481\end{array}$ & $\begin{array}{l}41,55 \pm 12,50 \\
36,63 \pm 8,73\end{array}$ & 0,011 \\
\hline $\begin{array}{l}\text { Ameliyat Öyküsü? } \\
\text { Var } \\
\text { Yok }\end{array}$ & $\begin{array}{l}84 \\
435\end{array}$ & $\begin{array}{l}38,48 \pm 10,77 \\
36,71 \pm 8,77\end{array}$ & 0,104 \\
\hline $\begin{array}{l}\text { Kronik Rahatsızlık } \\
\text { Evet } \\
\text { Hayır }\end{array}$ & $\begin{array}{l}53 \\
466\end{array}$ & $\begin{array}{l}42,58 \pm 13,63 \\
36,36 \pm 8,26\end{array}$ & $\mathbf{0 , 0 0 3}$ \\
\hline
\end{tabular}

ergenlerde 20 farklı ülkede uyku düzenine ilişkin otuz çalışmanın gözden geçirildiği bir metaanaliz, uyku süresinin cinsiyete, yaşa ve coğrafi bölgeye göre değiştiğini doğruluyordu. Bu çalışmaya göre;kızlar erkeklerden daha fazla uyuyor (okul zamanında günde $11 \mathrm{dk}$, okul dışı günlerde $29 \mathrm{dk}$ fazla), uyku süresi yaşla birlikte azalıyor (her yaş için günde 14 dakika) ve ülkeler arasında ergenlerin uyku süresinde büyük farklılıklar gösteriyor (Asya ülkelerindeki ergenler her gece Amerikalılardan 40-60 dakika Avrupalılardan 60-120 dakika daha az uyumaktadır) (29). Bizim araştırmamızda uyku bozukluğu yaşayan çocuk oranının çok fazla olması üzerinde ciddiyetle düşünülmesi gereken bir konudur. Çünkü uyku, çocukların sağlığı ve iyiliği için çok önemlidir (30). Sadece fiziksel ve duygusal gelişimde değil, bilişsel işlevlerde ve kardiyovasküler sağlığı geliştirmede de etkilidir $(9,31)$. Bu bağlamda çalışmamızda uyku bozukluğu nedenlerini saptamak ve önlemek için etken faktörlerin değerlendirmesi yapılmıştır.

Çalışmamızda baba eğitim düzeyi düşük, ekonomik durumu kötü, anne-babasıyla beraber yatan, cep telefonu sahibi olan ve kronik hastalığ 1 olan çocuklarda ÇUBÖ puanı daha yüksek bulunmuştur. Cinsiyet, anne eğitim seviyesi, çocuğun kendine ait odası olması, uyumadan iki saat kadar önce yiyecek ve içecek tüketimi, internet bağlantısı olması, ameliyat öyküsü olması çocuklarda uyku bozukluğuna anlamlı etki etmemiştir (Tablo 3). Düşük sosyoekonomik düzeyi olan aile çocuklarında uyku bozukluğu olabilir (32,33). Baba eğitim seviyesi düşüklüğü ve anne baba ile beraber yatma ekonomik durumun kötü olmasına sıklıkla eşlik edebilecek faktörler olduğu için bu gruplarda çocuklarda daha fazla uyku bozukluğu görülmüss olabilir. Ebeveynle aynı odada uyuyan çocuklarda daha fazla uyku bozukluğu olduğu bazı çalışmalarda gösterilmiştir. Ebeveynin çocuğa uykuda eşlik etmesi, çocukların uykuya başlama ve sürdürmedeki rahatsızlıklarından kaynaklanabilir (25). Çalışmamızda bu nedensel ayrım yapılamamıştır.

Çalışmamızda cep telefonu sahibi çocuklar ÇUBÖ'den istatistiksel olarak anlamlı derecede daha yüksek puan almışlardır (Tablo 3). Televizyon, sosyal medya, film ve video oyun içeren ekran medya aygıtlarını kullanmak uyku sorunları görülme olasılığını artırır. Bu durum ekran için ayrılan zamanın uykunun yerini almasından, ekrandaki mavi ışı̆̆ın melatonin üretimini baskılamasından ve uykuyu geciktirmesinden, ekran medyasındaki içeriklerin uykuyu engellemesinden kaynaklanabilir $(34,35)$. Çalışmamızın bulguları ve literatür bilgileri bu konuda 
Tablo 4. Obezite ile uyku bozukluğu arasındaki ilişki

\begin{tabular}{lccc}
\hline \multirow{2}{*}{ Percentil dağılımı } & \multicolumn{3}{l}{ Uyku bozukluğu } \\
\cline { 2 - 4 } & Yok & Var & $\mathrm{X}^{2}, \mathrm{p}$ \\
\hline \multirow{2}{*}{ Zayıf } & $11-35,5$ & $\mathrm{n}-\%$ & \\
Normal & $151-42,8$ & $202-57,2$ & $1,4290,489$ \\
Fazla kilolu ve obez & $51-37,8$ & $84-62,2$ &
\end{tabular}

örtüşmektedir.

Çalışmamızda çocukların \%10,2'sinde kronik hastalık bulunmaktadır (Tablo 1). Görülen bu kronik hastalıklar ağırlıklı olarak solunum sistemi hastalıklarıdır (alerji: \%24,5 astım: \%22,6 bronşit: $\% 9,4)$. Ayrıca çocukların \%16,2'si daha önce cerrahi operasyon geçirmiştir (geniz eti op: $\% 25,0$ bademcik op. : \%22,6 fitık op.: \%14,3 kemik kırık op.: \%10,7). Çocuklarda kronik hastalıklar genellikle astım ve allerji gibi solunum yolu hastalıklarıdır ve bu hastalıkların uyku bozukluğunu artırıcı ilişkisi bulunmaktadır $(16,36,37)$. Çalışmamızda da kronik hastalığı olan çocuklarda daha yüksek ÇUBÖ puanları saptanmıştır (Tablo 3).

Uykuyu etkileyebilecek bir faktör olarak uyumadan önce yiyecek ve içecek tüketimi sorguladık ve uyku ile ilişkisini çalışmamızda inceledik. Hafif bir santral sinir sistemi uyarıcısı olan kafein, uyku düzenini bozar. Yatmadan hemen önce alınan orta düzeyde kafein dozunun uyku bozukluğu üzerinde önemli etkileri vardır $(38,39)$. Çocuklar arasında birincil kafein kaynakları kahve, çay ve gazlı içeceklerdir (40). Araştırmamızdaki katılımcı öğrencilerden gün içerisinde hiç çay tüketmeyen çocuk oranı $\% 26,8$, hiç kahve tüketmeyen çocuk oranı \%91,7, hiç kola tüketmeyen çocuk oranı \%76,3' tür. Öğrenciler uyumadan ortalama 2 saat önce bir şeyler yiyip içmektedirler. Çalışmamızda uyumadan önce yiyecek ve içecek tüketimi ile uyku bozukluğu arasında ilişki bulunmamıştır (Tablo 3). Brambilla ve ark. (41) da yaptığg çalışmada yatmadan önce yiyecek ve içecek tüketiminin uykuya etkisini saptayamamıştır.

Uyku bozukluğu ile obezite arasındaki ilişki bilim dünyasında önemli bir ilgi odağı olmuştur $(10,42)$. Birçok çalışmada uyku bozukluğunun obeziteyi artırdığ1 görülse de (42-46) obez olan çocuk ve ergenlerde uyku süresinin daha uzun olduğunu gösteren çalışmalar da mevcuttur (47). Çalışmamızda zayıf ve normalin üstü percentil değerine sahip olan çocuklarda uyku bozukluğu oranı, normal percentil değerine sahip çocukların uyku bozukluğu oranından daha yüksek tespit edilmiş olmakla birlikte aralarındaki ilişki anlamlı değildir. İyi dinlenmiş bireylerin aksine yeterli uyku almayanlarda, iştah düzenleyen anahtar hormonlardan leptin seviyesi azalırken, ghrelin seviyeleri artarak açlık hissine neden olur. Yetersiz uyku süresi, kötü beslenme, azalmış insülin duyarlılığ 1 , hiperglisemi ve yaygın kardiyometabolik risk faktörleri ile de ilişkilidir (13). Uyku, çocukluk çağ 1 obezitesinin önlenmesinde dikkate alınması gereken önemli bir faktördür. Uyku süresi uzatılarak çocukluk çağı obezitesi prevalansı azaltılabilir. Bu nedenle uyku müdahaleleri küresel bir sağlık sorunu haline gelmiş çocukluk çağı obezitesi için potansiyel önleyici olabilir (10).

Uyku, yaş, kültürel değişikler ve coğrafi bölgeler ile farklılık gösterdiği için tek bir bölgede belli bir kültürel benzerlikte olan çocuklarda yapılan bu çalışma sonuçları tüm çocuk ve ergenlere genellenemez. Ancak çalışmanın beslenme tipi açısından Hatay ili içerisinde yapılmış olması önemlidir. Ayrıca uyku ve obezite arasındaki çift yönlü ilişkiden dolayı nedensel faktörleri belirlemek güç olsa da sonuçlar bize çocukluk çağında uyku bozukluğunun yüksek prevalansa sahip olduğunu göstermiştir.

\section{Sonuç}

Uyku bozukluğu yaşayan önemli bir yüzdede çocuk ve ergen vardır. Uyku bozukluğunun, çocuk gelişimi, bilişsel aktivasyonlar ve diğer hastalıklar için etkisi göz önüne alındığında, çocuklarda uyku problemlerinin ve nedenlerinin tanınarak uyku düzeni sağlanması çok önemlidir. Bu amaçla ekran medya aygıtları ile yiyecek ve içecek konusunda özenli davranılmalıdır. Çocuklar mümkün olduğu kadar anne ve babasının yanında uyumamalı, hayatın ilk anlarından itibaren çocuk ve ergenlere iyi bir uyku sağlanmalıdır. Sağlıklı uykunun obeziteyi engellediğini gösteren çalışmalar mevcuttur, bununla birlikte çalışmamızda uyku bozukluğu ve obezite arasında ilişki saptanmamıştır. Fazla kilolu ve obez çocuklar üzerinde yapılacak ulusal düzeyde daha büyük ölçekli çalışmalar ile obezite ve uyku bozukluğu arasındaki ilişki daha açık bir şekilde ortaya konularak, politika yapıcıların dikkati bu konuya çekilebilir ve bu sayede uyku bozukluğunu önleyecek müdahalaler ile çocukluk çağı obezitesinin önüne geçilebilir 


\section{Etik}

Etik Kurul Onayı: Araştırma öncesi Hatay Dörtyol İlçe Milli Eğitim Müdürlüğ̈̈’nden gerekli izinler ve Hatay Mustafa Kemal Üniversitesi Girişimsel Olmayan Klinik Araştırmalar Etik Kurulu'ndan 14.01.2021 tarih ve 17 numaralı karar ile etik onay alınmıştır.

Çıkar Çatışması: Yazarlar tarafından çıkar çatışması bildirilmemiştir.

Finansal Destek: Yazarlar tarafindan finansal destek almadıkları bildirilmiştir.

\section{Kaynaklar}

1. Ash T, Agaronov A, Young TL, Aftosmes-Tobio A, Davison KK. Family-based childhood obesity prevention interventions: a systematic review and quantitative content analysis. International Journal of Behavioral Nutrition and Physical Activity 2017;14:113.

2. Heslehurst N, Vieira R, Akhter Z, Bailey H, Slack E, Ngongalah $\mathrm{L}$, et al. The association between maternal body mass index and child obesity: A systematic review and meta-analysis. PLOS Medicine 2019; 16:e1002817.

3. Organization WH. Overweight and obesity. Geneva: World Health Organization; 2020 [cited 202128 April].

4. Erkuran H, Karadeniz H. Çocukluk Çağında Obezite. Sağlık ve Toplum 2019;29:12-9.

5. Rito AI, Buoncristiano M, Spinelli A, Salanave B, Kunešová M, Hejgaard T, et al. Association between Characteristics at Birth, Breastfeeding and Obesity in 22 Countries: The WHO European Childhood Obesity Surveillance Initiative-COSI 2015/2017. Obesity Facts 2019;12:226-43.

6. Sağlık Bakanlığ Örgütü Avrupa Bölge Ofisi. Türkiye Çocukluk Çağı (İlkokul 2. Sınıf Öğrencileri) Şişmanlık Araştırması Cosi-Tur 2016. Ankara: Sağlık Bakanlığı Yayınları Yayın No:1080;2017.

7. Esen İ, Ökdemir D. Çocukluk çağı obezitesi: tanım, etiyoloji ve klinik değerlendirme. Firat Tip Dergisi/Firat Med J 2018;23:929.

8. Yılmaz M, Kundakçı GA, Dereli F, Oztornacı BO, Cetişli NE. İlköğretim öğrencilerinde yaş ve cinsiyete göre obezite ve ilişkili özellikler obezite ve ilişkili faktörler. Güncel Pediatri 2019;17:127-40.

9. Liu X, Liu L, Owens JA, Kaplan DL. Sleep Patterns and Sleep Problems Among Schoolchildren in the United States and China. Pediatrics 2005; 115:241.

10. Chen X, Beydoun MA, Wang Y. Is sleep duration associated with childhood obesity? A systematic review and meta-analysis. Obesity 2008;16:265.

11. Felső R, Lohner S, Hollódy K, Erhardt É, Molnár D. Relationship between sleep duration and childhood obesity: Systematic review including the potential underlying mechanisms. Nutrition, Metabolism and Cardiovascular Diseases 2017;27:751-61.

12. Bhargava S. Diagnosis and management of common sleep problems in children. Pediatrics in Review-Elk Grove 2011;32:91.

13. Gohil A, Hannon TS. Poor Sleep and Obesity: Concurrent Epidemics in Adolescent Youth. Frontiers in Endocrinology 2018;9.
14. Association AP, Association AP. DSM 5. American Psychiatric Association 2013;70.

15. Short MA, Gradisar M, Gill J, Camfferman D. Identifying Adolescent Sleep Problems. PLOS ONE 2013;8:e75301.

16. Lewandowski AS, Ward TM, Palermo TM. Sleep problems in children and adolescents with common medical conditions. Pediatric Clinics 2011;58:699-713.

17. Akçay D, Akçay BD, Bozkurt ÖH. Reliability and validity of Turkish Sleep Disturbance Scale for Children. Anatolian Journal of Psychiatry 2020;21:70-7.

18. Neyzi O, Günöz H, Furman A, Bundak R, Gökçay G, Darendeliler F. Türk çocuklarında vücut ağırlığı, boy uzunluğu, baş çevresi ve vücut kitle indeksi referans değerleri. Çocuk Sağlığı ve Hastalıkları Dergisi 2008;51:1-14.

19. Dündar C, Öz H. Obesity-related factors in Turkish school children. The Scientific World Journal. 2012.

20. Erem C (2015). Prevalence of overweight and obesity in Turkey. IJC Metabolic \& Endocrine 2015;8:38-41.

21. World Health Organization. Taking action on childhood obesity (No. WHO/NMH/PND/ECHO/18.1). World Health Organization 2018.

22. Hales CM, Fryar CD, Carroll MD, Freedman DS, Ogden CL. Trends in obesity and severe obesity prevalence in US youth and adults by sex and age, 2007-2008 to 2015-2016. JAMA 2018;319:1723-25.

23. Ekström S, Hallberg J, Kull I, Protudjer JLP, Thunqvist P, Bottai M, et al. Body mass index status and peripheral airway obstruction in school-age children: a population-based cohort study. Thorax 2018;73:538-45.

24. Kabel AM, Al Thumali AM, Aldowiala KA, Habib RD, Aljuaid SS. Sleep disorders in a sample of students in Taif University, Saudi Arabia: The role of obesity, insulin resistance, anemia and high altitude. Diabetes \& Metabolic Syndrome: Clinical Research \& Reviews 2018;12:549-54.

25. Roberts CM, Harper KL, Bistricky SL, Short MB. Bedtime behaviors: Parental mental health, parental sleep, parental accommodation, and children's sleep disturbance. Children's Health Car 2020;49:115-33.

26. Lewien C, Genuneit J, Meigen C, Kiess W, Poulain T. Sleeprelated difficulties in healthy children and adolescents. BMC Pediatr 2001;1:11.

27. Mong JA, Cusmano DM. Sex differences in sleep: impact of biological sex and sex steroids. Philos Trans R Soc Lond B Biol Sci 2016;371:20150110.

28. Wang G, Zhang J, Lam SP, L SX, Jiang Y, Sun W, Wing YK. Ten-year secular trends in sleep/wake patterns in Shanghai and Hong Kong school-aged children: a tale of two cities. Journal of Clinical Sleep Medicine 2019;15:1495-502

29. Olds T, Blunden S, Petkov J, Forchino F. The relationships between sex, age, geography and time in bed in adolescents: a meta-analysis of data from 23 countries. Sleep medicine reviews 2010;14:371-8.

30. Matricciani L, Paquet C, Galland B, Short M, Olds T. Children's sleep and health: a meta review. Sleep medicine reviews 2019;46:136-50.

31. Sun J, Wang M, Yang L, Zhao M, Bovet P, Xi B. Sleep duration and cardiovascular risk factors in children and adolescents: A systematic review. Sleep medicine reviews 2020;101338. 
32. El-Sheikh M, Bagley EJ, Keiley M, Elmore-Staton L, Chen E, Buckhalt JA. Economic adversity and children's sleep problems: multiple indicators and moderation of effects. Health Psychol 2013;32:849-59.

33. Muller D, Paine SJ, Wu LJ, Signal TL. How long do preschoolers in Aotearoa/ New Zealand sleep? Associations with ethnicity and socioeconomic position. Sleep Health 2019;5:452-8.

34. Hisler GC, Hasler BP, Franzen P, Clark DB, Twenge JM. Screen media use and sleep disturbance symptom severity in children. Sleep Health 2020;6:731-42..

35. Guerrero MD, Barnes JD, Chaput JP, Tremblay MS. Screen time and problem behaviors in children: exploring the mediating role of sleep duration. International Journal of Behavioral Nutrition and Physical Activity 2019;16:1-10.

36. Yuksel H, Sogut A, Yilmaz O, Demet M, Ergin D, Kirmaz C. Evaluation of sleep quality and anxietydepression parameters in asthmatic children and their mothers. Respir Med 2007;101:25504.

37. Sivertsen B, Hysing M, Elgen I, Stormark KM, Lundervold AJ. Chronicity of sleep problems in children with chronic illness: a longitudinal population-based study. Child Adolesc Psychiatry Ment Health 2009;3:22.

38. Hindmarch I, Rigney U, Stanley N, Quinlan P, Rycroft J, Lane J. A naturalistic investigation of the effects of day-long consumption of tea, coffee and water on alertness, sleep onset and sleep quality. Psychopharmacology 2000;149:203-16.

39. Drake C, Roehrs T, Shambroom J, Roth T. Caffeine effects on sleep taken 0,3 , or 6 hours before going to bed. Journal of Clinical Sleep Medicine 2013;9:1195-200.
40. Watson EJ, Banks S, Coates AM, Kohler MJ. The relationship between caffeine, sleep, and behavior in children. Journal of Clinical Sleep Medicine 2017;13:533-43.

41. Brambilla P, Giussani M, Pasinato A, Venturelli L, Privitera F, Miraglia Del Giudice EM, Chiappini, E. Sleep habits and pattern in 1-14 years old children and relationship with video devices use and evening and night child activities. Ital J Pediatr 2017;43:7.

42. Locard E, Mamelle N, Billette A, Miginiac M, Munoz F, Rey S. Risk factors of obesity in a five year old population. Parental versus environmental factors. Int J Obes Relat Metab Disord 1992;16:721-9.

43. Snell EK, Adam EK, Duncan GJ. Sleep and the body mass index and overweight status of children and adolescents. Child Dev 2007;78:309-23.

44. Liu X, Forbes EE, Ryan ND, Rofey D, Hannon TS, Dahl RE. Rapid eye movement sleep in relation to overweight in children and adolescents. Arch Gen Psychiatry 2008;65:924-32. doi: 10.1001/archpsyc.65.8.924

45. Miller MA, Kruisbrink M, Wallace J, Ji C, Cappuccio FP. Sleep duration and incidence of obesity in infants, children, and adolescents: a systematic review and meta-analysis of prospective studies. Sleep 2018;41: zsy018.

46. Hui LL, Nelson EA, Yu LM, Li AM, Fok TF. Risk factors for childhood overweight in 6- to 7-y-old Hong Kong children. Int J Obes Relat Metab Disord 2003;27:1411-8.

47. Ulutaş A, Atla P, Say Z, Sarı.E. Okul çağındaki 6-18 yaş arası obez çocuklarda obezite oluşumunu etkileyen faktörlerin araştırılması. Zeynep Kamil Tıp Bülteni 2014;45:192-6. 